Rapid Reviews COVID-19

\title{
Reviews of "COVID-19 herd immunity in the Brazilian Amazon"
}

\section{Cesar Victora ${ }^{1}$}

${ }^{\mathbf{1}}$ Federal University of Pelotas, Brazil

Published on: Feb 07, 2021

License: Creative Commons Attribution 4.0 International License (CC-BY 4.0). 
Since our solicitation of reviews, this preprint has been published in Science journal and the link to the published manuscript can be found here.

To read the original manuscript, click the link above.

Summary of Reviews: This manuscript is an important contribution to the literature regarding the correction and interpretation of seroprevalence estimates. However, the use of blood donors as the sample population may have biased the result and the authors' suggestion that Manaus may have reached herd immunity is at odds with the increase in cases there.

\title{
Reviewer 1 (Cesar Victora) |
}

\author{
RR:C19 Strength of Evidence Scale Key. \\ प्रिप्र = Misleading \\ प्रिप्र = Not Informative \\ प्राप्र = Potentially Informative \\ प्राप्र = Reliable

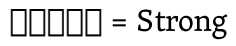

To read the reviews, click the links below. 